\title{
UMA CIÊNCIA MODERNA SE REFAZ: POSSIBILIDADES AGENCIADAS ENTRE A TEORIA ATOR-REDE E A PSICOLOGIA
}

\author{
A MODERN SCIENCE REMAKES ITSELF: AGENCIED \\ POSSIBILITIES BETWEEN ACTOR-NETWORK THEORY AND \\ PSYCHOLOGY
}

\author{
João Paulo Roberti Junior ${ }^{1}$
}

\section{RESUMO}

Por se constituir em um cenário moderno, a Psicologia tem a característica particular de rever com elevada frequência as suas próprias categorias analíticas e os seus preceitos teórico-metodológicos. Um desses momentos de questionamento vem das reflexões levantadas pela Teoria Ator-Rede. Esta pesquisa, com delineamento qualitativo e de problematização teórica, tem como objetivo colocar em discussão uma série de reflexões que se têm realizado sobre a Teoria Ator-Rede e suas contribuições para a Psicologia. O foco neste trabalho está no modo como são tratadas as associações entre humanos e não humanos e nas categorias social, representação social, indivíduo, sujeito/objeto e tudo mais que hoje auxilia os psicólogos a acelerarem suas explicações. É importante destacar a percepção de que, na Psicologia, ora a ênfase das compreensões está no sócio (entendido como o humano), que na maior parte das vezes deixa subentendido que aquilo que chamamos de relações sociais é algo que se estabelece exclusivamente entre humanos e pessoas, ora o acento está no técnico (entendido como o não humano), destacando as potencialidades dos equipamentos e dos softwares, os quais muitas vezes deixam claro que o humano está refém dessas técnicas, como se elas determinassem novas modalidades de relação e constituição entre humanos. Os resultados apontam para novos diálogos necessários à Psicologia, colocando-a em movimento com novas possibilidades a serem assimiladas para o seu campo.

Palavras-chave: Psicologia. Teoria Ator-Rede. Sociotécnico.

\section{ABSTRACT}

Because it is constituted in a modern setting, psychology has the particular characteristic of review with high frequency their own analytical categories and their theoretical and methodological precepts. One of those questioning moments comes from the reflections raised by the Actor-Network Theory. This research, with

\footnotetext{
${ }^{1}$ Mestrando em Antropologia Social (UFSC). E-mail: joaoroberti@gmail.com
} 
UMA CIÊNCIA MODERNA SE REFAZ: POSSIBILIDADES AGENCIADAS ENTRE A TEORIA ATOR-REDE E A PSICOLOGIA João Paulo Roberti Junior

qualitative and theoretical disputes design, aims to put in discussion a series of reflections that have been done on the Actor-Network Theory and its contributions to psychology. The focus of this work will be the way they are treated associations between humans and non-humans and categories, social, social representation, individual, the subject / object and everything that today helps psychologists to accelerate their explanations. It is important to emphasize the perception that in psychology, now the emphasis of understanding are in the social (understood as the human), which most often infers that what we call social relations is something that takes place exclusively between humans and people, now the emphasis is on technical (understood as the non-human), highlighting the potential of equipment and software, most of which often leaves understood that the human is for these techniques, as if they RESULT IN new forms of relationship and constitution among humans. The results point to new dialogues needed to psychology, placing it on the go with new possibilities to be assimilated to his farm.

Keywords: Psychology. Actor-Network Theory. Sociotechnical.

\section{INTRODUÇÃO}

As teorias, no geral, afirmam práticas e visões de mundos (FERREIRA et al., 2010). Nessa perspectiva, a Psicologia tem expressado, nos dias atuais, uma complexa rede de significações a respeito das mudanças e dos preceitos teóricometodológicos que perpassam sua teoria. $\mathrm{O}$ efeito de problematizar conceitos e teorias em Psicologia reveste-se na construção da qualidade de ação à qual a Psicologia é fadada.

Ao longo de minha trajetória, tenho levantado algumas discussões sobre as articulações entre a Teoria Ator-Rede e a Psicologia. As preocupações a que me detenho estão voltadas para o modo como são tratadas as associações entre humanos e não humanos e para as apreciações da Psicologia como um saber moderno. Nesse saber moderno, tenho buscado desestabilizar categorias que já estão sob outros efeitos e associações, tais como o social, a rede, o indivíduo, o sujeito/objeto e tantos outros atores que aparecem nessa associação entre Teoria Ator-Rede e Psicologia.

As bases teóricas nas quais a Psicologia se ampara possibilitam uma reflexão que possa dialogar com novas problematizações contemporâneas à sua própria 
UMA CIÊNCIA MODERNA SE REFAZ: POSSIBILIDADES AGENCIADAS ENTRE A TEORIA ATOR-REDE E A PSICOLOGIA João Paulo Roberti Junior

ciência. Esse movimento "é uma singular relação com o próprio tempo, que adere a este e, ao mesmo tempo, dele toma distâncias; [...] através de uma dissociação e um anacronismo" (AGAMBEM, 2009, p. 59). As teorias que coincidem muito plenamente com a época, aderindo-a perfeitamente, não são contemporâneas, porque não conseguem vê-la, não podendo manter fixo o olhar sobre ela. Dentro dessas questões, envolvem-se alguns psicólogos, que hoje têm investido somente em aplicação de teorias, sem mesmo problematizarem ou saberem por quais categorias estão operando.

Nesse sentido, o presente trabalho é um convite para pensar a Psicologia através de um movimento contemporâneo. Exige-se ser contemporâneo, também, dos textos e dos autores que circundam a sua própria ciência. Pensando nas discussões que serão aqui propostas, procuro aderir ao movimento de criar uma inatualidade sobre o que temos trabalhado na Psicologia hoje. Nesse sentido, adoto uma postura contemporânea na Psicologia, não apenas percebendo-a no escuro do presente, posto que nele se aprende e se volta à luz, mas também dividindo e interpolando o tempo, colocando-o sempre em constante relação com 0 atual (AGAMBEM, 2009), a partir de novas problematizações.

Essa postura leva a pensar sobre como a Psicologia tem se afirmado com a sua própria herança, ao tentar se estabelecer como um conhecimento moderno. $O$ percurso que proponho neste trabalho é desafiador e, antes de tudo, é um arriscarse em público, dado o cruzamento metodológico e teórico que será proposto. Para as discussões que sugiro, adotei a reflexão sobre a Teoria Ator-Rede (TAR - Teoria Ator-Rede, em Português - ou ANT - do inglês Actor Network Theory), também denominada de sociologia das associações (LATOUR, 2012), a fim de problematizar algumas notas que possibilitam uma reflexão teórico-metodológica na própria Psicologia. Essa análise proporciona uma reflexão sobre a Psicologia, estabelecendo tópicos para uma autocrítica.

Realizarei uma discussão teórica (re)pensando posturas e concepções metodológicas que até então eram impossíveis no campo moderno da Psicologia, salientando que, embora Bruno Latour, teórico ascendente da TAR, não estabeleça 
UMA CIÊNCIA MODERNA SE REFAZ: POSSIBILIDADES AGENCIADAS ENTRE A TEORIA ATOR-REDE E A PSICOLOGIA João Paulo Roberti Junior

em sua literatura reflexões sistematizadas da Psicologia, encontramos em seu trabalho moções e pontes que podem ser estabelecidas com diversos ramos do conhecimento. Todavia, a "sua forma de pensar os estudos científicos permite refletir a Psicologia sobre novos prismas" (TSALLIS et al., 2006, p. 59). Embora grande parte da literatura de Bruno Latour já se encontre traduzida para a Língua Portuguesa (LATOUR, 1994, 2001a, 2002, 2012), muitos conceitos ainda não são conhecidos no meio acadêmico e, principalmente, na própria Psicologia. Ao longo deste artigo, procuro sistematizar os conceitos em notas reflexivas, engendrando discussões com a Psicologia.

Então, como já afirmado, dado que essa abordagem não é de uso comum, serão apresentados alguns debates e conceitos-chave que irão habilitar e intermediar o diálogo com a Psicologia. Dessa forma, serão negadas dicotomias entre natureza e cultura, o que está atualmente sob a denominação da Teoria AtorRede em Bruno Latour, trazendo discussões contemporâneas para o presente artigo.

\section{A PSICOLOGIA COMO ESTÉTICA MODERNA SOB NOVAS PERSPECTIVAS}

A Psicologia iniciou sua constituição entrelaçada nos limites e teorias da época em que foi fundada. Expor e esclarecer a história da Psicologia nos auxilia a tornar possível pensar a respeito de algumas dicotomias ainda existentes e principalmente alertar-nos para a falibilidade de uma ciência que se firmou moderna.

A Psicologia surgiu como uma disciplina específica, na Alemanha, a partir do século XIX. Seu nascimento esteve atribuído a Wilhelm Wundt, que obteve o título de fundador da Psicologia como ciência experimental (ARAÚJO, 2005). O objeto da Psicologia tornou-se, então, o da experiência imediata dos sujeitos, embora ele não estivesse interessado, primordialmente, nas diferenças individuais entre estes. Experiência imediata é a experiência tal como o sujeito a vive antes de se colocar a pensar sobre ela, antes de comunicá-la e antes de "conhecê-la". É, em outras 
UMA CIÊNCIA MODERNA SE REFAZ: POSSIBILIDADES AGENCIADAS ENTRE A TEORIA ATOR-REDE E A PSICOLOGIA João Paulo Roberti Junior

palavras, a experiência tal como se dá. Contudo, Wundt não reduz a tarefa da Psicologia à descrição dessa experiência.

O método para investigação da ciência psicológica era o das ciências naturais, sob outra perspectiva. O experimento e a observação tornaram-se, a partir disso, formas hegemônicas de investigar os objetos psicológicos. Wundt foi, então, eleito o fundador da Psicologia científica não apenas pela fundação do laboratório de Psicologia, mas, sobretudo, pelo que ele passou a representar (ARAÚJO, 2005). Porém, essa curta história de "fundação" da ciência psicológica é notadamente complementada por um "passado longo", de forma que muitas concepções e preocupações são também rastreadas do mundo Antigo, em especial na Grécia e em Roma, com a Filosofia (HOTHERSALL, 2006).

Todavia, em grande medida, a história da Psicologia científica mostra-se com o afastamento da Filosofia. Segundo Arendt (2010, p. 32), isso revela a necessidade de "lançar a Psicologia num debate caracterizado por controvérsias que até hoje permanecem praticamente sem solução". Essas controvérsias referem-se à dicotomia entre as ciências do espírito e as ciências da natureza, proposta por Wundt. É interessante notar que ela nasce como uma ciência intermediária, entre as ciências da natureza e as ciências da cultura.

Desse passado, a Psicologia ainda decai sobre a controvérsia de que possui "uma herança moderna". Essa herança moderna atrela a Psicologia a um fórum privilegiado decorrente desta história: a questão da pluralidade de concepções dentro da própria Psicologia. Tal pluralidade de concepções singulares não tem sido debatida na busca por uma unidade pelo firmamento de sua pluralidade.

A relação que Latour estabelece entre a ciência pronta e a ciência em construção se mostra como uma importante entrada para se pensar em discussões sobre a constituição da ciência e particularmente da Psicologia. Em diversos momentos, algumas abordagens da Psicologia têm buscado uma causa final para a resolução dos problemas e de todas as controvérsias, de forma que a natureza aparece como a causa que permitiu a resolução de alguns conflitos na busca pela estabilização como ciência. Tomamos como exemplo algumas abordagens, como o 
UMA CIÊNCIA MODERNA SE REFAZ: POSSIBILIDADES AGENCIADAS ENTRE A TEORIA ATOR-REDE E A PSICOLOGIA João Paulo Roberti Junior

behaviorismo, o cognitivismo etc. Assim, demasiadas vezes nos deparamos com colegas que desejam atacar concepções e visões de mundo, dentro da própria Psicologia. Nesses momentos, em geral, aciona-se uma chave para a discussão: a natureza. A esse respeito, Latour (2012, p. 151) aponta: "a natureza é causa final da resolução de todas as controvérsias".

Dessa maneira, "uma vez que a resolução de uma controvérsia é a causa da representação da Natureza, e não a consequência, nunca poderemos usar o resultado - Natureza - para explicar como e por que uma controvérsia foi resolvida" (LATOUR, 2011, p. 153). Essas bifurcações na explicação levaram a uma divisão de concepções dentro da Psicologia e, consequentemente, a muitas razões para explicar e refutar essa singularidade hegemônica que ela atrela.

Contudo, a diversidade do campo psicológico é comumente questionada (FERREIRA, 2010), estando envolta da disparidade desse campo como cruzamento teórico-metodológico. Nessa hegemonia da natureza, uma das principais marcas da Psicologia é a produção de uma "cultura psicológica" (BERNARD, 1983) como o efeito de sua difusão.

Latour (1999b), em uma discussão sobre a universalidade da psicanálise, engendra um pensamento que pode servir como unificador das diversas psicologias: eus fabricados artificial e publicamente. Assim, nessa "cultura psicológica", o projeto de emancipação dos atores libertos de suas correntes é revestido por meio das abordagens naquilo que os determina e essa visão inibe a possibilidade de recalcitrância na Psicologia (FERREIRA, 2010). Essa possibilidade dada aos sujeitos e indivíduos (ambos utilizados na Psicologia, muitas vezes sem as devidas problematizações ou, pior, como sinônimos) faz com que eles fiquem na posição de "ingênuos", como um desconhecimento imposto ao sujeito ingênuo, que empobrece, por exemplo, a relação terapêutica e as diversas possibilidades de o psicólogo conhecer o que está investigando, contribuindo com um intercâmbio entre investigador e investigado.

O modo de produção de inúmeras subjetividades na Psicologia não deve ser visto como algo ruim, mas produtivo. Porém, a sua capacidade de recalcitrância 
UMA CIÊNCIA MODERNA SE REFAZ: POSSIBILIDADES AGENCIADAS ENTRE A TEORIA ATOR-REDE E A PSICOLOGIA João Paulo Roberti Junior

ainda imposta aos sujeitos muitas vezes dificulta o trabalho e a constituição da própria Psicologia. Visões científicas prontas e acabadas ainda limitam o trabalho e dificultam as práticas de novas constituições na Psicologia. A Teoria Ator-Rede fornece subsídios para se problematizar uma nova possibilidade de se pensar 0 sujeito na Psicologia e os objetos de investigação desta. Porém, ela, a Teoria AtorRede, não deve ser tomada como pronta e acabada, e sim como uma forma de articular as subjetividades e associações sem buscar a prática de purificação de uma teoria. As orientações diversas na Psicologia somente se legitimam na medida em que estão na prática de suas ações. Além disso, Ferreira (2010) propõe o modelo designado de Máquina de Múltiplas Capturas ${ }^{2}$ para tentar explicar a pluralidade do campo psicológico.

Destaca-se, nesse viés, a afirmação de Ferreira (2010, p. 49) de que "a pluralidade da Psicologia parece ser colocada como uma anomalia deste saber em relação aos demais, e não como uma marca singular" (FERREIRA, 2010, p. 49). Assim, é admirável o que Bruno Latour, baseado nos Estudos Científicos de Isabelle Stengers e Vinciane Despret, afirma sobre a Política Epistemológica. Para esses autores, a pluralidade é tomada como algo positivo. Nas palavras de Latour (1999b, p. 220):

The good ones are those that allow for the connection of widely different phenomena and thus generate even more recognition of unexpected differences by engaging a few entities in the life and fate of many others. The bad ones are those which, because they had had such a local success try to produce generality, not through connection of new differences, but by the discounting of all remaining differences as irrelevant.

\footnotetext{
${ }^{2}$ Esse modelo ocorre em algumas fases. Em um primeiro momento, o autor afirma que todas as "psicologias" advêm de uma diversidade de experiências sociais ou psicotécnicas, como, por exemplo, a busca de verdades via confissão, o exame das nossas experiências pessoais, visando preveni-las das ilusões, o controle da loucura etc. No segundo momento, essas práticas demandariam um lastro de verdades, buscando-as em métodos e conceitos das ciências naturais, como a física e a biologia. Assim, desse cruzamento de conceitos e métodos científicos com práticas sociais, surgiriam as diversas orientações psicológicas (FERREIRA, 2010).
} 
UMA CIÊNCIA MODERNA SE REFAZ: POSSIBILIDADES AGENCIADAS ENTRE A TEORIA ATOR-REDE E A PSICOLOGIA João Paulo Roberti Junior

Todas as ponderações sobre a pluralidade da Psicologia auxiliam sempre na busca por uma reflexão fecunda acerca da sua própria constituição. Todavia, a procura por uma unidade para adotar pressupostos de progressos em direção à verdade recai de frente, também, como oposição ao conhecimento comum, fazendo assim com que o conhecimento científico seja glorificado (FERREIRA, 2010). Esse viés já estaria contra o que Bruno Latour propõe, que não existe verdade e erro, assinalando um combate entre vencedores e vencidos, sempre na busca por uma classificação para dissimular a origem inconfessável das entidades naturais e sociais (LATOUR, 2012).

Portanto, segundo Latour (2004, p. 221), "generalization should be a vehicle for travelling through as many differences as possible - thus maximizing articulations - and not a way of decreasing the number of alternative versions of the same phenomena". Assim, contra o princípio excludente entre bons e maus ou entre vencedores e vencidos, o princípio de simetria fornece pistas para refletir sobre as relações impostas nessas fabricações de subjetividades na imposição de uma cultura psicológica.

O princípio de simetria sugerido em David Bloor e Michel Callon, e posteriormente em Latour (1999b, 2001), propõe uma ruptura epistemológica, enunciada no Racionalismo (FERREIRA, 2010). Nesse sentido, não existe diferença entre verdade e erro, e os princípios deveriam ser explicados pelos mesmos indícios.

A antiga altercação do internalismo versus externalismo na produção da ciência recai sobre o conhecimento ora produzido fora de sua rede coletiva, em ideias prontas, ora em um fenômeno social, sem entender a especificidade da ciência em que é construída (FERREIRA, 2010). A Teoria Ator-Rede rompe, então, com as dicotomias essencialistas no momento em que refuta a dicotomia entre ciência e sociedade na produção de conhecimento e, assim, da Psicologia.

Pensando na definição do que é a Psicologia (uma ciência da conduta? Dos fenômenos? Do comportamento? Do inconsciente? Das representações sociais?), revela-se um nó que, segundo Ferreira (2010, p. 52), seria "frouxo" e que se 
UMA CIÊNCIA MODERNA SE REFAZ: POSSIBILIDADES AGENCIADAS ENTRE A TEORIA ATOR-REDE E A PSICOLOGIA João Paulo Roberti Junior

concentra e conecta com demandas e problemas individuais, com redes específicas de práticas científicas. Porém, por ter uma trajetória científica moderna, os vínculos consensuais são importados da natureza com o intuito de demonstrar que "quem tem a natureza em seu campo vence, sejam quais foram as suas desvantagens" (LATOUR, 2011, p. 145).

Demonstra-se, então, nas suas análises, o resultado dessa trajetória científica moderna: humanos de um lado e não humanos de outro (LATOUR, 1994, 1999b). Isso significa que a concepção modernista "conferia aos sujeitos liberdade e autonomia enquanto considerava os objetos como regidos pela necessidade e determinação" (PEREIRA, 2010, p. 47). Essa análise também se dirige dentro da própria Psicologia, com os híbridos "psicólogos sociais", que, com as suas representações sociais, buscam construir um lugar para o social, economizando suas explicações. Assim, assumir o papel de que o objeto da Psicologia é também fabricado, distribuído nas redes e articulado entre humanos e não humanos é conceber que nada está dado de antemão. Talvez quando entendermos que a tarefa da Psicologia pode ser a de buscar condições objetivas e também subjetivas do conhecimento, acompanhando as alianças entre humanos e não humanos, a partir da qual se faz e se constitui a subjetividade, daremos um passo a mais em nossa ciência.

Eu poderia ter dito "objetivado" ou "reificado" ou "realizado" ou "materializado" ou "gravado", mas estas palavras implicam um agente humano todo poderoso impondo sua vontade numa matéria amorfa, enquanto os não humanos também agem, deslocam objetivos e contribuem para a sua redefinição (LATOUR, 1994, p. 38).

Trata-se, portanto, de avaliar também simetricamente no âmbito de sua prática e pesquisa o modo como se dá a associação entre humanos e não humanos. É "ultrapassar a dupla separação moderna entre humanos e os não humanos, defendendo que se dê igual importância de tratamento para a produção tanto dos primeiros quanto dos segundos" (FREIRE, 2006, p. 49). 
UMA CIÊNCIA MODERNA SE REFAZ: POSSIBILIDADES AGENCIADAS ENTRE A TEORIA ATOR-REDE E A PSICOLOGIA João Paulo Roberti Junior

A ANT apresenta-se como uma alternativa para a concepção da ação dos indivíduos: "nem a suposta liberdade do indivíduo tomado isoladamente nem o ambiente, o inconsciente e a sociedade, como estruturas causais" (PEREIRA, 2010, p. 47), satisfazem a análise da explicação da ação de um ator ${ }^{3}$. Considera-se, nesse sentido, uma dimensão que concebe e refuta oposições entre interior e exterior, mental e material, sujeito e objeto.

Para ilustrar esse processo, temos o exemplo da arma na composição de práticas (BONAMIGO, 2010). A posição é que não podemos prever o que pode acontecer quando se junta uma pessoa e uma arma, pois, como visto, não há uma essência do sujeito ou do objeto. Assim, no encontro entre uma pessoa e uma arma, um novo objetivo pode ser constituído, para uma nova ação, deslocando-se para pensar que "havendo a criação de um novo vínculo que modifica tanto a pessoa quando a arma" (BONAMIGO, 2010, p. 172). Desse modo, os artefatos reais são sempre partes de instituições hesitantes em sua condição mista de mediadores (LATOUR, 2001), transformando-se e alterando-se, não como um todo ou como entidades dicotômicas entre sujeito-objeto, mas, pensando na metonímia da arma, como um "sujeito-arma" (BRUNO, 2010).

Deleuze e Guattari (1980) fazem a distinção entre armas e ferramentas (como, por exemplo, a faca como uma arma e o martelo como uma ferramenta). O questionamento é: por que o martelo pode ser ferramenta e não arma? A diferença é de agenciamento, de uso, de modo de funcionamento. Não há nada em si, nada na faca, que faça dela uma arma ou uma ferramenta, não existe uma essência do técnico. Essa diferença envolve outras potencialidades, assim como quando as pesquisas em Psicologia falam sobre as drogas, por exemplo. Todos os elementos podem matar e podem fazer algo de interessante, mas isso não é feito de antemão. Essas coisas têm a ver com modos de agenciamento. Um faz o outro fazer alguma coisa. Nós somos sempre ligeiramente surpreendidos por aquilo que fazemos.

\footnotetext{
${ }^{3}$ Latour $(2001,2012)$ considera ambos, humanos e não humanos, como atores. Conceber um ator é conceber "tudo que tem agência, que produz diferenças, desvios, transformações na distribuição da ação numa rede sociotécnica e na fabricação do mundo" (BRUNO, 2010, p. 11).
} 
UMA CIÊNCIA MODERNA SE REFAZ: POSSIBILIDADES AGENCIADAS ENTRE A TEORIA ATOR-REDE E A PSICOLOGIA João Paulo Roberti Junior

Surpreendido não é um valor prévio de surpresa, mas da concepção de que não sabemos o que pode ocorrer de antemão.

Nessa perspectiva, uma concepção mentalista ou ambientalista nos convida a mudar as mentes, os sentimentos ou os ambientes dos homens, em vez de refletir as ações postas no mundo em que vivemos. Afinal, é tentador acreditar que são mentes e contextos agressivos que matam e não as associações com armas, por exemplo. Portanto, as ações ora são localizadas nos indivíduos, como se fizessem parte de sua natureza, ora são localizadas na sociedade, entendendo-se como uma construção social (BRUNO, 2010) e um lugar privilegiado. Pensar, dessa maneira, que a arma nos inscreve em uma série de relações que não eram possíveis sem ela, considerando que os não humanos possuem agência e que produzem efeitos no mundo, modificando nossas ações e nossa cognição, é um importante fator contributivo à Psicologia. $O$ social não pode ser entendido como algo que antecede nossas práticas ou mesmo como um modelo operativo-descritivo das ações, mas, sim, como algo que é tecido e retecido na rede de articulações.

A Teoria Ator-Rede revela-se, desse modo, como um dispositivo teóricometodológico de análise que é capaz de enfrentar o desafio contemporâneo de levar em conta a multiplicidade e a heterogeneidade das ações das pessoas, considerando na sua gênese os não humanos. Conduzindo a descrição das relações que se estabelecem entre os elementos heterogêneos que compõem o fluxo da ação, sem fixar em algum lugar as ações dos humanos, podemos trazer contribuições para o campo da Psicologia.

As relações são estabelecidas em um espaço fluido e constante, que, em lugar da essência, buscam uma "existência arriscada" (BONAMIGO, 2010, p. 177) para as ações e na análise destas na Psicologia. Dessa forma, o melhor que se pode fazer para caminhar na ação dos sujeitos é seguir os traços deixados pelos atores, isto é, "o que eles dizem e o que eles fazem, nos seus próprios termos" (PEREIRA, 2010, p. 49), e também o que dizem quando fazem.

Dada a sua herança moderna, a Psicologia tem como objeto de sua análise os humanos, dotados de consciência e intencionalidade. Como vimos, essa 
UMA CIÊNCIA MODERNA SE REFAZ: POSSIBILIDADES AGENCIADAS ENTRE A TEORIA ATOR-REDE E A PSICOLOGIA João Paulo Roberti Junior

concepção torna-se menos evidente quando consideramos não humanos na gênese da ação e de constituição da cognição. Nesse sentido, analisar o processo de rede e o processo cognitivo da ação na relação de humanos e não humanos marca incertezas quanto à natureza da ação.

A noção de rede concebe caminhos nos quais se pode pensar a natureza da ação, refletindo sobre o social não somente em termos de ação, mas também de produção. Pergunta-se, assim: quais os vínculos concebidos entre humanos e não humanos? Quais efeitos que tais vínculos produzem na gênese do processo cognitivo? O social, então, deixa novamente de se tornar um modelo operativodescritivo e/ou analítico por si só para pensar o processo que interfere na constituição dos fatos e da cognição.

Considerar os não humanos é, antes de tudo, afirmar que possuem "agência, produzem efeitos no mundo, modificam nossas ações, redefinem nossa cognição" (MORAES, 2004, p. 7). Os estudos e as afirmações de Latour auxiliam a perceber e repensar as informações e explicações postas sempre a priori na Psicologia, as quais são traduções de acelerações de nossas concepções (e muitas vezes servem como descritivo-qualificadores), oferecendo e garantindo modelos transcendentais e ontológicos que são dados de antemão (como caixas-pretas) e não auxiliam a conhecer os vínculos entre humanos e não humanos.

Os não humanos, até então estudados como passivos, submetidos às ações humanas, são eles também atores que devem ser levados em conta por uma psicologia considerada como estética da cognição. Assim, longe de ser referida ao par sujeito-objeto a cognição passa a ser entendida a partir das articulações entre humanos e não humanos. Cognição híbrida, mestiça longe, portanto, das distinções que marcaram as pesquisas em psicologia: sujeito $X$ objeto, indivíduo $X$ sociedade, psicologia social $X$ cognitiva (MORAES, 2004, p. 9).

Para essas posturas serem multiplicadas, é necessário entender o curso da ação como processo de tradução, coexistindo em duas compreensões: 1) "o social desapareceu" (LATOUR, 2012, p. 157) e 2) "o social voltou como associação" (LATOUR, 2012, p. 159). Assim, o modo como os atores estão associados pode 
UMA CIÊNCIA MODERNA SE REFAZ: POSSIBILIDADES AGENCIADAS ENTRE A TEORIA ATOR-REDE E A PSICOLOGIA João Paulo Roberti Junior

levá-los a fazer outras ações. Isso mostra que uma força não permanece da mesma forma por todo o percurso - como um intermediário -, mas gera transformações fiéis diante dos numerosos eventos, desencadeados por outros mediadores que estão situados em toda a parte. Esse fato seria chamado de o "princípio de irredução", que significa que "a concatenação dos mediadores não traça as mesmas ligações e não requer o mesmo tipo de explicações como séquito de intermediários transportando uma causa" (LATOUR, 2012, p. 159). Nesse momento, esbarra-se com a ideia de que o social deve ser descrito, em vez de fornecer explicação.

Contudo, para designar algo como social, entendemos esse social não como uma força que respalda todos os atores, mas como uma conexão que transporta transformações, transformando em tradução. Aqui, tradução significa "uma relação que não transporta causalidade, mas induz dois mediadores à coexistência" (LATOUR, 2012, p. 159). Se uma causalidade parece ser transportada de um modo previsível e rotineiro, então ela é a prova de que outros mediadores foram mobilizados para tornar esse deslocamento simples e previsível.

Tradução, então, seria quando se interfere de um objeto para outro da ação, uma translação de objetos constituindo híbridos. Nessa perspectiva, podemos chegar à conclusão de que existem traduções entre mediadores que provocam associações possíveis de serem rastreáveis nessa possibilidade da dimensão da ação (humana e não humana). Qualquer trabalho assumido por um teórico da ANT deverá ampliar o repertório de atores, incluindo, neste, os objetos na gênese do processo da ação. A esse respeito, seguindo Segata (2012, p. 240), "o que Bruno Latour quer fazer recuperar, aqui, é a nossa capacidade de dar um passo a mais nas descrições, atentando-se ao esgotamento e aos muitos atuantes (actantes) desses eventos".

\section{CONSIDERAÇÕES FINAIS}

O estudo aqui apresentado pretendeu contribuir no sentido de apontar caminhos e direcionar ações para se pensar a influência da Teoria Ator-Rede na 
UMA CIÊNCIA MODERNA SE REFAZ: POSSIBILIDADES AGENCIADAS ENTRE A TEORIA ATOR-REDE E A PSICOLOGIA João Paulo Roberti Junior

Psicologia a partir de novos prismas. Avaliando que a Psicologia tem a característica bastante singular de rever, com uma frequência bastante acelerada, as suas próprias categorias analíticas e os seus preceitos teórico-metodológicos, o trabalho despontou nesse sentido, a fim de buscar rever e desestabilizar categorias e princípios da Psicologia partindo das reflexões da Teoria Ator-Rede.

Tal abordagem se traduziria, grosseiramente, em fazer pensar sobre uma Psicologia que considere as composições entre humanos e não humanos. Por alto, isso não parece distante do que comumente se faz em termos de pesquisa na área, mas basta uma revisão, ainda que superficial em alguns aspectos, para se notar duas ênfases nas pesquisas na área. A primeira é que, em geral, o destaque está no sócio (entendido como o humano) ou no social (definido em algum lugar), em que são enfatizadas as formas de relação entre as pessoas, que na maior parte das vezes deixam claro que aquilo que chamamos de relações sociais é algo que se estabelece exclusivamente entre humanos/pessoas. A segunda é que ocasionalmente o acento está no técnico (entendido como o não humano), e então é possível encontrar trabalhos contemporâneos que tratam da inovação tecnológica, ressaltando as potencialidades das máquinas e dos softwares, deixando subentendido, muitas vezes, que eles determinam novas modalidades de relação e constituição nos humanos. Assim, esse sociotécnico assume a forma de um lugar técnico preenchido ou sustentador de relações sociais. Enfim, tanto de uma maneira como de outra, sócio e técnico aparecem como fenômenos distintos na Psicologia.

Diante dessa constatação, a Teoria do Ator-Rede possibilita dar subsídios para um tratamento diferenciado aos temas das humanidades, e em especial da Psicologia, pensando o sócio e o técnico constituídos simetricamente como uma rede que descentra agências na sua capacidade de tradução (constituição de híbridos). Nesse caminho, de modo amplo, o objetivo deste artigo é o de aproximar o pensamento da Teoria Ator-Rede da Psicologia, na busca do estabelecimento de tópicos para uma reflexão teórico-metodológica no que diz respeito à noção do tratamento das associações entre humanos e não humanos em seus trabalhos e tudo o que vem sendo feito. 
UMA CIÊNCIA MODERNA SE REFAZ: POSSIBILIDADES AGENCIADAS ENTRE A TEORIA ATOR-REDE E A PSICOLOGIA João Paulo Roberti Junior

A Psicologia encontra nessa topologia heterogênea da rede sociotécnica uma matriz fértil para pesquisas acerca de processos e objetos que tradicionalmente permaneciam ora no exterior do seu campo de investigação, ora desprovidos de uma abordagem conceitual e metodológica pertinente (BRUNO, 2010, p. 14). Em linhas gerais, a ANT tem-se afirmado como um saber que rejeita a descrição do mundo "moderno" e a Psicologia, por ter se constituído como um campo de saber "moderno", sofre influências igualmente. Latour (2005) compreende a modernidade como um conjunto de práticas que, em muitas medidas, não coincide com a teoria; e a Psicologia, com sua forma moderna, concebe uma realidade bifurcada entre natureza e cultura. Porém, "as práticas de purificação, que se buscava na modernidade a fim de se obter meios pelos quais os coletivos (separadamente humanos e não humanos) pudessem se ampliar e progredir, só foram possíveis pelo contrário: a mistura deles" (RIFIOTIS et al., 2011).

A ANT propõe rever conceitos e divisões modernas, tais como a noção de coletivo, ator, rede, fetiche, representação social, agência etc. Essa última chama a atenção para a dimensão artefatual da participação dos objetos técnicos na gênese dos processos cognitivos. Conceber a ação como mediação (LATOUR, 2012, 1994) possibilita não definir um acontecimento por causas e consequências, mas um deslocamento de objetivos e ações. Dessa forma, a ação é deslocada, permitindo não definir de antemão uma relação de causa e efeito, mas considerando o deslocamento da ação e objetivando a participação dos não humanos na ação.

Nesse sentido, esta pesquisa buscou demonstrar a importância de a Psicologia permitir um diálogo e um passo a mais na sua matriz conceitual, com vistas a contribuir dentro de sua própria disciplina. Assim, discussões teóricas, principalmente na Psicologia, auxiliam na sua própria e necessária atualização, além de possibilitar que determinadas críticas importantes não passem despercebidas pelos profissionais da área, trazendo engrandecimento em termos de teoria, método e prática.

\section{REFERÊNCIAS}


UMA CIÊNCIA MODERNA SE REFAZ: POSSIBILIDADES AGENCIADAS ENTRE A TEORIA ATOR-REDE E A PSICOLOGIA

João Paulo Roberti Junior

AGAMBEN, Giorgio. O que é o contemporâneo? E outros ensaios. Chapecó: Argos, 2009.

AKRICH, M.; LATOUR, B. A summary of a convenient vocabulary of the semiotics for human and nonhuman assemblies. In: BIJKER, W.; LAW, J. (Ed.). Shaping

Technology, Building Society: studies in sociotechnical change. Cambridge: MIT Press, 1992. p. 123-146.

ARAÚJO, S. F. Wilhelm Wundt e o Estudo da Experiência Imediata. In: JACÓVILELA, A. M.; FERREIRA, A. A.; PORTUGAL, F. T. (Org.). História da Psicologia: rumos e percursos. Rio de Janeiro: NAU, 2005. p. 123-144.

ARENDT, R. J. O que nós psicólogos podemos aprender com a teoria ator-rede? Interações, v. 12, n. 22, p. 57-86, 2006.

ARENDT, R. J. Enfim: e a tua Psicologia, como é, e para quê? In: FERREIRA, A. L. et al. Teoria Ator-Rede e Psicologia. Rio de Janeiro: NAU, 2010. p. 24-44.

BERNARD, M. A Psicologia. In: CHATELÊT, F. (Org.). História da Filosofia: Ideias, Doutrinas. Lisboa: Dom Quixote, 1983. v. 7, p. 7-28.

BIJKER, W.; PINCH, T. The Social Construction of Facts and Artifacts: or how the Sociology of Science and Sociology of Technology might benefit each other. In: BIJKER, W.; PINCH, T.; HUGHES, P. (Org.). The Social Construction of Technological Systems. Cambridge: MIT Press, 1989. p. 17-50.

BLOOR, D. Anti Latour. Studies in History and Philosophy of Sciences, v. 30, n. 1, p. 81-112, 1999.

BLOOR, D. Conhecimento e Imaginário Social. São Paulo: Editora da Unesp, 2009.

BONAMIGO, I. S. A Teoria Ator-Rede como dispositivo teórico-metodológico de análise da produção de violências na contemporaneidade. In: FERREIRA, A. A. L. et al. Teoria Ator-Rede e Psicologia. Rio de Janeiro: NAU, 2010. p. 164-180.

BRUNO, Fernanda. Prefácio. In: FERREIRA, A. A. et al. Teoria Ator-Rede e Psicologia. Rio de Janeiro: NAU, 2010. p. 8-16.

CALLON, Michel. Society in the Making: the study of technology as a tool for sociological analysis. In: BIJKER, W.; PINCH, T.; HUGHES, P. (Ed.). The Social Construction of Technological Systems. Cambridge: MIT Press, 1989. p. 83-104. 
UMA CIÊNCIA MODERNA SE REFAZ: POSSIBILIDADES AGENCIADAS ENTRE A TEORIA ATOR-REDE E A PSICOLOGIA João Paulo Roberti Junior

DELEUZE, G.; GUATTARI, F. Mille plateaux. Paris: Éditions de Minuit, 1980.

FREIRE, L. Seguindo Bruno Latour: notas para uma antropologia simétrica. Comum, Rio de Janeiro, v. 11, n. 26, p. 46-65, 2006.

HOTHERSALL, David. História da Psicologia. São Paulo: McGraw-Hill, 2006.

LATOUR, Bruno. Factures/Fractures: from de concept of network to the concept of attachment. AUTUMN, p. 20-36, 1999a.

LATOUR, Bruno. On Recalling ANT. In: HASSARD, J.; LAW, J. (Ed.). ActorNetwork-Theory and After. Oxford: Blackwell, 1999b. p. 15-25.

LATOUR, Bruno. A Esperança de Pandora: ensaios sobre a realidade dos estudos científicos. Bauru: Edusc, 2001.

LATOUR, Bruno. Reflexão Sobre o Culto Moderno dos Deuses Fe(i)tiches. Bauru: Edusc, 2002.

LATOUR, Bruno. Un Monde Pluriel Mais Commun: entretiensavec François Ewald. Luxembourg: Éditions de L'Albe, 2003.

LATOUR, Bruno. Jamais Fomos Modernos: ensaio de antropologia simétrica. São Paulo: Editora 34, 1994.

LATOUR, Bruno. Reagregando o Social: uma introdução à teoria do ator-rede. Bauru: Edusc, 2012.

LATOUR, Bruno; WOOLGAR, Steve. La Vie de Laboratoire: la production des faits scientifiques. Paris: La Découverte, 2006.

LAW, John. After ANT: complexity, naming and topology. In: HASSARD, J.; LAW, J. (Ed.). Actor-Network-Theory and After. Oxford: Blackwell, 1999. p. 1-14.

LAW, John. After Method: mess in social science research. Londres: Routledge, 2004.

LAW, John. Traduction/Trahison: notes on ANT. Convergencia, México, v. 13, n. 42, p. 47-72, set.-dez. 2006.

MORAES, Márcia. A ciência como rede de atores: ressonâncias filosóficas. História, Ciências e Saúde, Manguinhos, v. 11, maio-ago. 2004. 
UMA CIÊNCIA MODERNA SE REFAZ: POSSIBILIDADES AGENCIADAS ENTRE A TEORIA ATOR-REDE E A PSICOLOGIA João Paulo Roberti Junior

NOBRE, J. C. A. A produção de conhecimento na atualidade: dos sólidos às redes de fluxos. 2003. Dissertação (Mestrado em Psicossociologia de Comunidades e Ecologia Social) - Programa Eicos, Instituto de Psicologia, Universidade Federal do Rio de Janeiro, Rio de Janeiro, 2003.

PALMA, N. S.; RODRIGUES, V. A.; MORAES, M. Psicólogos em forma[t]ação: cartografias de um esboço de autoanálise. Estudos e Pesquisas em Psicologia, v. 12, p. 623-647, 2012.

PEREIRA, Henrique. Jung e o laboratório da alma: a psicologia analítica examinada pela teoria ator-rede. Curitiba: Juruá, 2010.

RIFIOTIS, T. et al. Redes sociotécnicas: hibridismos e multiplicidade de agências na pesquisa da Cibercultura. In: LACERDA, J.; BARRETO, V. (Org.). Comunicação, Educação e Vivência: saberes e vivências em teorias e pesquisa na América Latina. João Pessoa: EDUFPB; Natal: EDUFRN, 2011. p. 236-265.

SEGATA, Jean. Reagregando o Social: uma introdução à Teoria Ator-Rede. Ilha: Revista de Antropologia, Florianópolis, v. 14, n. 1, 2012.

TSALLIS, A. C. et al. O que nós psicólogos podemos aprender com a teoria atorrede? Interações, v. 12, n. 22, p. 57-86, 2006. 